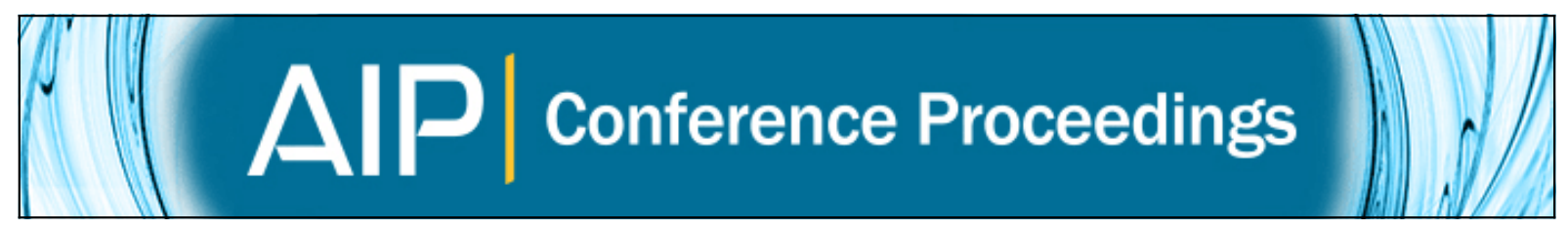

\title{
Simulation of ion-induced nucleation in the CLOUD chamber
}

Sebastian Ehrhart, Siegfried Schobesberger, Jasper Kirkby, Joachim Curtius, and CLOUD Collaboration

Citation: AIP Conference Proceedings 1527, 339 (2013); doi: 10.1063/1.4803272

View online: http://dx.doi.org/10.1063/1.4803272

View Table of Contents: http://scitation.aip.org/content/aip/proceeding/aipcp/1527?ver=pdfcov

Published by the AIP Publishing

\section{Articles you may be interested in}

Kinetics of ion-induced nucleation in a vapor-gas mixture

J. Chem. Phys. 123, 104704 (2005); 10.1063/1.2018632

Ion and nano-particle measurement in ion-induced nucleation process

AIP Conf. Proc. 534, 665 (2000); 10.1063/1.1361954

Molecular simulation of ion-induced nucleation in water vapor

AIP Conf. Proc. 534, 151 (2000); 10.1063/1.1361836

Ion-induced nucleation. II. Polarizable multipolar molecules

J. Chem. Phys. 103, 8993 (1995); 10.1063/1.470089

Ion-induced nucleation: A density functional approach

J. Chem. Phys. 102, 913 (1995); 10.1063/1.469158 


\title{
Simulation of ion-induced nucleation in the CLOUD chamber
}

\author{
Sebastian Ehrhart ${ }^{* \dagger}$, Siegfried Schobesberger** Jasper Kirkby ${ }^{\dagger}$, Joachim \\ Curtius* and the CLOUD collaboration \\ *Institute for Atmospheric and Environmental Sciences, Goethe University, Frankfurt am Main, \\ Hessen, Germany \\ ${ }^{\dagger} \mathrm{ERN}, \mathrm{CH}-1211$ Geneva, Switzerland \\ ** Department of Physics, University of Helsinki, P.O. Box 64, FI-00014 University of Helsinki,
} Finland

\begin{abstract}
A comparison between the binary Sulphuric Acid Water NUCleation model SAWNUC and CLOUD results is presented. Comparison includes direct comparison with a battery of particle counters of various counting efficiencies and APi-TOF charged cluster distribution. A good agreement is found for nucleation rates at various temperatures.
\end{abstract}

Keywords: Ion Induced Nucleation, CLOUD experiment, nucleation modelling

PACS: $82.70 . \mathrm{Rr}, 82.60 . \mathrm{Nh}, 64.60 . \mathrm{Q}-$

\section{INTRODUCTION}

The contribution of aerosols to climate is one of the most uncertain factor in global warming [1]. Currently the contribution of nucleation to atmospheric aerosol concentrations is topic of debate. Nucleation could contribute to some extent to the global aerosol population [2]. To understand nucleation is therefore an important part in understanding earth climate. The current understanding of nucleation in the atmosphere suggests a fundamental role of sulphuric acid. Nucleation can be enhanced by ionising radiation and the contribution of stabilising trace vapours [3]. Especially the contribution of Galactic Cosmic Rays (GCR), that are the major source of ions in the atmosphere, on nucleation is currently up for debate $[4,5]$. To investigate the influence of ionising radiation, temperature and atmospheric trace gases on particle formation the CLOUD experiment was set up at CERN.

This contribution will present the results of a comparison between the results of binary nucleation experiments in CLOUD and the Sulphuric Acid Water NUCleation model [6]. This model allows to compare the CLOUD results with previous studies on nucleation $[7,8]$ and ion thermodynamics $[9,10]$. Furthermore the model is used to investigate some general aspects of nucleation experiments.

\section{MODELLING}

To calculate the influence ionisation on binary sulphuric acid water nucleation the SAWNUC model was created [6]. Evaporation rates in the model are based on measured 
charged cluster thermodynamics for small clusters [9, 10], bigger clusters are treated with classical thermodynamics and evaporation of intermediate charged clusters is based on interpolation. Neutral evaporation rates for the clusters containing two and three $\mathrm{H}_{2} \mathrm{SO}_{4}$ molecules are based on measurements and classical thermodynamics [11]. The model was adjusted to represent conditions in the CLOUD chamber. These adjustments include counting efficiencies of particle counters [12] and losses to the chamber wall. The particle counter measurements for low temperature binary nucleation events (both neutral and ion induced) are compared with SAWNUC. This comparison allows to investigate how counting efficiencies influence nucleation experiments.

\section{RESULTS}

Beside the direct comparison between previous work on binary nucleation and CLOUD, SAWNUC was also used for a variety of further detailed studies. It is important to take the shape of CPC counting efficiencies into account. The shape influence the time at which the first particles occur as well as the peak particle formation rate. This is especially important under conditions with low growth rates. The charged cluster thermodynamics from $[6,9,10]$ is compared to measurements done in CLOUD with an APi-TOF measuring negative polarity [13]. By removing cluster evaporation SAWNUC can be used to model situations of kinetically limited nucleation. This allows to investigate effects that occur in these systems, such as depletion of $\mathrm{H}_{2} \mathrm{SO}_{4}$ and help interpreting the results of nucleation and growth experiments. Furthermore the influence of wall losses on $\frac{d \log (J)}{d \log \left[\mathrm{H}_{2} \mathrm{SO}_{4}\right]}$ was investigated. This gives insight how the experimental set up affects interpretation of nucleation experiments.

\section{ACKNOWLEDGMENTS}

We would like to thank CERN for supporting CLOUD with important technical and financial resources, and for providing a particle beam from the CERN Proton Synchrotron. This research has received funding from the EC Seventh Framework Programme (Marie Curie Initial Training Network "CLOUD-ITN" no. 215072, MC-ITN "CLOUD-TRAIN" no. 316662, and ERC-Advanced "ATMNUCLE" grant no. 227463), the German Federal Ministry of Education and Research (project nos. 01LK0902A and 01LK1222A), the Swiss National Science Foundation (project nos. 200020_135307 and 206620_130527), the Academy of Finland (Center of Excellence project no. 1118615), the Academy of Finland (135054, 133872, 251427, 139656, 139995, 137749, 141217, 141451), the Finnish Funding Agency for Technology and Innovation, the Nessling Foundation, the Austrian Science Fund (FWF; project no. P19546 and L593), the Portuguese Foundation for Science and Technology (project no. CERN/FP/116387/2010), the Swedish Research Council, Vetenskapsrådet (grant 2011-5120), the Presidium of the Russian Academy of Sciences and Russian Foundation for Basic Research (grants 08-02-91006-CERN and 12-02-91522-CERN), and the U.S. National Science Foundation (grants AGS1136479 and CHE1012293). 


\section{REFERENCES}

1. I. P. on Climate Change. Working Group I., Climate Change 2007 : the physical science basis : working group I contribution to the Fourth Assessment Report of the IPCC., Cambridge University Press, 2007, ISBN 9780521705967.

2. J. Merikanto, D. V. Spracklen, G. W. Mann, S. J. Pickering, and K. S. Carslaw, Atmospheric Chemistry and Physics 9, 8601-8616 (2009).

3. J. Kirkby, J. Curtius, J. Almeida, E. Dunne, J. Duplissy, S. Ehrhart, A. Franchin, S. Gagne, L. Ickes, A. Kurten, A. Kupc, A. Metzger, F. Riccobono, L. Rondo, S. Schobesberger, G. Tsagkogeorgas, D. Wimmer, A. Amorim, F. Bianchi, M. Breitenlechner, A. David, J. Dommen, A. Downard, M. Ehn, R. C. Flagan, S. Haider, A. Hansel, D. Hauser, W. Jud, H. Junninen, F. Kreissl, A. Kvashin, A. Laaksonen, K. Lehtipalo, J. Lima, E. R. Lovejoy, V. Makhmutov, S. Mathot, J. Mikkila, P. Minginette, S. Mogo, T. Nieminen, A. Onnela, P. Pereira, T. Petaja, R. Schnitzhofer, J. H. Seinfeld, M. Sipila, Y. Stozhkov, F. Stratmann, A. Tome, J. Vanhanen, Y. Viisanen, A. Vrtala, P. E. Wagner, H. Walther, E. Weingartner, H. Wex, P. M. Winkler, K. S. Carslaw, D. R. Worsnop, U. Baltensperger, and M. Kulmala, Nature 476, 429-433 (2011), ISSN 0028-0836.

4. $\quad$ K. S. Carslaw, R. G. Harrison, and J. Kirkby, Science 298, 1732-1737 (2002).

5. J. Kazil, R. Harrison, and E. Lovejoy, Space Science Reviews 137, 241-255 (2008), ISSN 0038-6308.

6. E. R. Lovejoy, J. Curtius, and K. D. Froyd, J. Geophys. Res. - Atmospheres 109, D08204 (2004).

7. S. M. Ball, D. R. Hanson, F. L. Eisele, and P. H. McMurry, J. Geophys. Res. 104, 23709-23718 (1999), ISSN 0148-0227.

8. D. R. Hanson, and E. R. Lovejoy, The Journal of Physical Chemistry A 110, 9525-9528 (2006).

9. J. Curtius, K. D. Froyd, and E. R. Lovejoy, The Journal of Physical Chemistry A 105, 10867-10873 (2001).

10. K. D. Froyd, and E. R. Lovejoy, The Journal of Physical Chemistry A 107, 9812-9824 (2003).

11. J. Kazil, and E. R. Lovejoy, Atmospheric Chemistry and Physics 7, 3447-3459 (2007).

12. D. Wimmer, K. Lehtipalo, A. Kürten, F. Kreissl, A. Metzger, J. Kangasluoma, A. Franchin, F. Riccobono, A. Kupc, J. Vanhanen, J. Mikkilä, T. Petäjä, M. Kulmala, and J. Curtius, AMTD submitted (2013).

13. H. Junninen, M. Ehn, T. Petäjä, L. Luosujärvi, T. Kotiaho, R. Kostiainen, U. Rohner, M. Gonin, K. Fuhrer, M. Kulmala, and D. R. Worsnop, Atmospheric Measurement Techniques 3, 1039-1053 (2010). 